\title{
The susceptibility of Streptococcus mutans to antibacterial photodynamic therapy: a comparison of two different photosensitizers and light sources
}

\author{
Neda HAKIMIHA ${ }^{1}$, Farzaneh KHOEI ${ }^{1}$, Abbas BAHADOR ${ }^{2}$, Reza FEKRAZAD ${ }^{3}$
}

1- Laser Research Center of Dentistry (LRCD), School of Dentistry, Tehran University of Medical Sciences, Tehran, Iran.

2- Microbiology Department, School of Medicine, Tehran University of Medical Sciences, Tehran, Iran.

3- Laser Research Center in Medical Sciences (LRCMS), AJA University of Medical Sciences - Laser Research Center of Dentistry (LRCD), School of Dentistry, Tehran University of Medical Sciences, Tehran, Iran.

Corresponding address: Farzaneh Khoei - Laser Research Center of Dentistry, School of Dentistry, Tehran University of Medical Sciences - North Kargar Street, Tehran, Iran - Phone/Fax: +982188015017 - Mobile phone:+989121501884 - e-mail: khoeifarzaneh@yahoo.com

Submitted: January 15, 2013 - Modification: November 17, 2013 - Accepted: November 25, 2013

\section{ABSTRACT}

\begin{abstract}
Streptococcus mutans is the main etiological agent for dental caries. Recently, photodynamic therapy (PDT) has been introduced as a new modality in bacterial decontamination. Objective: This in vitro study was carried out to evaluate the susceptibility of Streptococcus mutans to antibacterial PDT using two different photosensitizers and light sources. Material and Methods: Standard suspensions of S. mutans were exposed to laser light at $662 \mathrm{~nm}$ and Radachlorin ${ }^{\circledR}$ or LED $630 \mathrm{~nm}$ in combination with Toluidine blue O (TBO). Radiation-only groups, photosensitizer alone, and groups with no treatment were used as controls. Bacterial suspension from each treatment was subcultured onto the surface of Mueller-Hinton agar plates and bacterial growth was assessed. The results were analyzed by analysis of variance and Tukey test $(p<0.05)$. Results: PDT with TBO and Radachlorin ${ }^{\circledR}$ significantly reduced $S$. mutans viability, whereas no difference was observed between two groups of PDT. In the groups treated just with the photosensitizer or irradiated alone, no significant reduction of $S$. mutans colonies was observed. Conclusion: $S$. mutans colonies were susceptible to either $662 \mathrm{~nm}$ laser or LED light in the presence of Radachlorin ${ }^{\circledR}$ and TBO respectively with no priority.
\end{abstract}

Keywords: Streptococcus mutans. Antibacterial agents. Photodynamic therapy.

\section{INTRODUCTION}

Dental caries is the most common disease in the world, and comes about as the result of plaque biofilm formation on the teeth inside the mouth ${ }^{1,27}$. The main etiological factor for caries on smooth surfaces is the group of streptococci, mainly mutans streptococci (MS), most notably Streptococcus mutans. For the development of cariogenic biofilms, the colony forming of MS on tooth surface has an important role as this bacterium is able to cause oral $\mathrm{pH}$ reduction following the production of acids, leading to tooth demineralization ${ }^{18,23}$.

Anti caries procedures can be categorized into two phases: prevention and treatment strategies. In the prevention phase, caries control is based on limited consumption of sugar and good oral hygiene, which is achieved through mechanical and chemical removal of the biofilm, including brushing and use of antimicrobial agents ${ }^{4,21}$.

However, these methods have some limitations such as mechanical damage to the oral mucosa in patients with mechanoblistering disease caused by brushing or scraping, as well as antibacterial-resistance of biofilm species and the difficulty to maintain therapeutic concentrations of antimicrobials in the oral cavity ${ }^{18,27}$.

In the treatment phase and removal of caries, it is difficult to detect the exact caries-removal endpoint. A caries lesion consists of two different layers: the outer layer, known as infected dentin, which is characterized by softened dentin with a large number of bacteria and the inner layer, known as affected dentin, contaminated with 
fewer bacteria, that is usually subjected to remineralization. However, the clinical distinction of these two regions is extremely difficult, and usually conventional methods involve the removal of both infected and affected layers which can result in pulp exposure in deep carious lesions. As such, conservative cavity preparations behind affected dentin can cause remineralization and prevent accidental pulp exposure ${ }^{13}$.

Since caries are localized infections, as well as considering the limitation of traditional treatments, alternative protocols such as Photodynamic Therapy (PDT) can be proposed ${ }^{2}$. PDT is a therapeutic process, involving the combination of light and photosensitive agents called photosensitizers ${ }^{14}$.

The photodynamic process is a two-step protocol, in which target cells are exposed to a photosensitizer and irradiated with a harmless light in the maximum absorption of the sensitizer wavelength, leading to the production of singlet oxygen and free radicals that can damage essential components of the cells, such as plasma membrane and DNA, or of modifying metabolic activities in an irreversible way, thus possibly resulting in cell death ${ }^{9,13}$.

PDT has several applications in Dentistry such as the treatment of oral cancer, bacterial, viral and fungal infections and photodynamic diagnosis of the malignant oral lesions ${ }^{19}$.

Antimicrobial PDT (a-PDT) is a localized, nonthermal and non-invasive antimicrobial method to decrease bacterial contamination in oral infections $\mathbf{s}^{3,14,22}$.

Several studies have illustrated that PDT has a strong effect on a large number of oral grampositive and negative bacteria, using different photosensitizers and light sources $7{ }^{73,15}$. However, the results of these studies are somewhat different and are not always clear. Hence, the purpose of this study was to compare the antibacterial effect of PDT on $S$. mutans with two different photosensitizers and light sources.

\section{MATERIAL AND METHODS}

Test microorganism and growth conditions Lyophilized Streptococcus mutans (ATCC 25175, obtained from Rayen Biotechnology Co. Ltd., Tehran, Iran) were rehydrated in brain heart infusion (BHI) broth (Merck KGaA, Darmstadt, Germany) and incubated in an aerobic atmosphere at $37^{\circ} \mathrm{C}$ for $48 \mathrm{~h}$. For experiments requiring cultures on plates, cultures grown in $\mathrm{BHI}$ broth were transferred onto brain heart infusion (Mueller-Hinton agar; Conda, Madrid, Spain) plates.

\section{Photosensitizers and light sources}

In this study two different photosensitizers and light sources were used:

Toluidine blue $\mathrm{O}$ (TBO) powder (Certistain ${ }^{\circledR}$, Merck KGaA, Darmstadt, Germany) was used and dissolved in distilled water to reach the concentration of $0.1 \mathrm{mg} / \mathrm{ml}$, where the filter was sterilized to obtain clear and homogenous solution. The light source for activation was Light Emitting Diode (LED) (FotoSan ${ }^{\circledR} 630$ LAD, CMS dental, Copenhagen, Denmark) with output intensity of 2.000-4.000 mW/ $\mathrm{cm}^{2}$, within 30 seconds.

Radachlorin ${ }^{\circledR}$ solution $0.35 \%$ (Rada-Pharma Co, Ltd., Moscow, Russia) was used which was activated by Diode Laser $662 \mathrm{~nm}$ (LAKHTA-MILON, SaintPetersburg, Russia) with fiber optic of $800 \mu \mathrm{m}$ with power of $300 \mathrm{~mW}$ and irradiation time of 30 seconds and energy density of $24 \mathrm{~J} / \mathrm{cm}^{2}$.

Fresh colonies of $S$. mutans from Mueller-Hinton (MH) Agar plates were suspended in BHI broth, and bacterial density was visually adjusted to a turbidity of 0.5 McFarland standard reagent. The exact density $(\mathrm{CFU} / \mathrm{mL})$ of each suspension was verified on $\mathrm{MH}$ Agar plates.

S. mutans solution was prepared for seven 96well $(7 \mathrm{~mm}$ diameter) flat-bottom plates with lids (Orange Scientific, Belgium) separately as below:

1) Laser+Radachlorin ${ }^{\circledR}\left(\mathrm{L}^{+} \operatorname{Rad}^{+}\right)$

2) LED+TBO (LED+ $\left.\mathrm{TB}^{+}\right)$

3) Laser ( $L^{+}$Rad $\left.{ }^{-}\right)$

4) LED (LED+ TB')

5) Radachlorin ${ }^{\circledR}\left(\mathrm{L}^{-} \mathrm{Rad}^{+}\right)$

6) TBO (LED- $\mathrm{TB}^{+}$)

7) Control (no light, no photosensitizer)

In each study well of the plates, $200 \mu \mathrm{L}$ of S. mutans suspension plus $200 \mu \mathrm{L}$ of related photosensitizer were added. In the groups of 3 (Laser), 4 (LED) and 7 (Control), $200 \mu \mathrm{L}$ of the sterile phosphate-buffered saline (PBS) was added to equalize the level of all the wells. Samples were then kept in the dark for 5 minutes before irradiation.

Irradiation was performed in a laminar flow hood (Besat, Tehran, Iran) in the dark under aseptic conditions. Light devices were fixed in vertical positions at the level of the wells. To prevent light transmission into neighboring wells, 15 wells of each plate, with 2-well distance between them, were selected and plates were covered with a black shield with an orifice corresponding to the diameter of the wells.

After the treatment, the plates were incubated overnight. The samples were then serially diluted in PBS. In order to evaluate bacterial viability, $50 \mu \mathrm{L}$ of each dilution were cultured on Mueller Hinton Agar and incubated for 24 hours at $37^{\circ} \mathrm{C}$ in a partial atmosphere of $5 \% \mathrm{CO}_{2}$. After incubation, the number of colony forming units per milliliter $(\mathrm{CFU} / \mathrm{ml})$ was determined. The results were logtransformed and analyzed by analysis of variance 
Table 1- Means \pm Standard deviation and P-value of the number of $\log 10$ obtained for the different groups

\begin{tabular}{ccc}
\hline Group & Mean \pm Standard Deviation & P Value \\
\hline L+ Rad+ & $6.43 \pm .47$ & $.000^{*}$ \\
LED+ TB+ & $6.34 \pm .40$ & $.000^{*}$ \\
L+ Rad- & $7.71 \pm .05$ & 0.889 \\
LED+ TB- & $7.70 \pm .07$ & 0.772 \\
L- Rad+ & $7.65 \pm .11$ & 0.414 \\
LED- TB+ & $7.69 \pm .09$ & 0.711 \\
Control & $7.79 \pm .09$ & - \\
\hline
\end{tabular}

*significant difference between study groups and control $(p<0.05$, Tukey test)

(ANOVA) and Tukey test using SPSS statistical software version 20. Statistical significance was defined as $\mathrm{p}<0.05$.

\section{RESULTS}

Table 1 shows the means and standard deviations of the number of log10 obtained for the studied groups.

The reduction of $S$. mutans viability in groups of PDT with TBO and Radachlorin ${ }^{\circledR}$ was statistically significant. There was no significant difference between the two groups of PDT, however significant difference was observed between the PDT and other groups.

In the groups treated just with the photosensitizer or irradiated alone, no significant reduction of colonies was observed.

\section{DISCUSSION}

The current study illustrated that Photodynamic Therapy (PDT) with both photosensitizers (PS) and their individual light sources led to a significant reduction in the viability of $S$. mutans with no significant difference between two groups of PDT (LED+TBO and Radachlorin ${ }^{\circledR}+$ Laser).

One of the photosensitizers that were used in this study was TBO. TBO is a cationic phenothiazine derivatives photosensitizer of affordable cost and with maximum absorption wavelength in the red light spectrum of $630 \mathrm{~nm}$, capable of inactivating both gram positive and gram negative bacteria. This is mainly due to its physical and chemical properties and hydrophilic features that allow its free passage across the bacterial membrane and consequently the attraction to the negatively charged potential of mitochondria, which allows direct action on this organelle ${ }^{16,21}$. Another article proposed that TBO may bind to the polyphosphates of the outer membrane and produce molecular damage to lipids and proteins, including membrane-bound enzymes ${ }^{24}$.

There is a large number of studies on the efficacy of TBO in PDT and most of them have confirmed the effectiveness of this photosensitizer $6,11,25,26,28,29$.

In the current study the light source for activating TBO was LED, while in other studies Laser was used instead. LED is a non-monochromatic light that has become a practical technology for PDT in the last few years, especially for irradiation of easily accessible tissue surfaces. The main advantages of LED over Laser are their low cost and ease configuration of LED arrays into different irradiation geometries ${ }^{16}$.

Rolim, et al. ${ }^{21}$ (2012) examined the antimicrobial activity of various photosensitizers against $S$. mutans with the same concentration by analyzing the generation of $\mathrm{O}_{2}$ and reported that amongst the photosensitizers of methylene blue (MB), toluidine blue ortho (TBO), malachite green (MG), eosin (EOS), erythrosine (ERI) and rose Bengal (RB), TBO is the only photosensitizer that effectively reduced $99.9 \%$ of these microorganisms.

Zanin, et al. ${ }^{29}$ (2006) used TBO with the concentration of $0.1 \mathrm{mg} / \mathrm{ml}$, similar to the current study, combined with LED in order to achieve the photodestruction of oral biofilm and reported that TBO-mediated PDT can significantly decrease the load of $S$. mutans in the biofilm. Giusti, et al. ${ }^{8}$ (2008) also stated that the greatest effect on $S$. mutans was obtained with TBO at $0.1 \mathrm{mg} / \mathrm{ml}$ in combination with LED which was in agreement with our results.

Furthermore, in another research, Lima, et al. ${ }^{13}$ (2009) confirmed that PDT with TBO was effective in killing oral microorganisms present in dentin caries produced in situ and may be a useful technique for eliminating bacteria from dentin carious lesions before restoration.

Radachlorin ${ }^{\circledR}$ was the other photosensitizer which was used in combination with laser 662 $\mathrm{nm}$. It is a chlorophyll a derivative, including mainly sodium chlorin e6 5 . Research on PDT with Radachlorin ${ }^{\circledR}$ is limited. However, some clinical trials on this sensitizer have clarified significant advantages such as very low toxicity in the dark, high contrast of tumor accumulation, much more 
rapid body evacuation (only two days), intensive absorption band at relatively large wavelengths where tissues are more transparent and finally the high phototoxicity ${ }^{10,20}$.

Fekrazad, et al. ${ }^{6}$ (2011) studied the antibacterial effect of PDT on S. mutans with He-Ne Laser $(633 \mathrm{~nm})$ and reached the conclusion that a combination of this laser with Radachlorin ${ }^{\circledR} 0.1 \%$ gel photosensitizer was more effective than single use of laser or Radachlorin ${ }^{\circledR}$ alone on reduction of S. mutans colony count (although cytotoxic effect of Radachlorin ${ }^{\circledR}$ was seen in the dark). This result is similar to our findings, but in our study Radachlorin ${ }^{\circledR}$ did not show any cytotoxic effet; this may be due to the different form and concentration of PS used in these two studies.

Vahabi, et al. ${ }^{26}$ (2011) declared that only PDT with TBO $0.1 \%$ and $633 \mathrm{~nm}$ diode laser at $3 \mathrm{~J} / \mathrm{cm}^{2}$ was effective in eliminating $S$. mutans, whereas PDT with Radachlorin ${ }^{\circledR}$ plus $662 \mathrm{~nm}$ laser had no effect on reducing the viability of $S$. mutans. Results of PDT with TBO confirmed the current finding, but the result of the current study with Radachlorin ${ }^{\circledR}$ was different. One possible explanation is that the laser parameters were not the same in these researches.

This study showed that neither of the light sources nor photosensitizers alone had any effect on S. mutans viability, which is in accordance to other similar articles ${ }^{12,17}$.

Based on the results of the current research and other in vitro and ex vivo studies, it appears that PDT can be helpful for elimination of cariogenic bacteria prior to restorative proceduth while minimizing the excavation of the affected dentine. Consequently, this can allow maximal preservation of tooth tissue and long term prognosis of the restored tooth can be predicted with minimal risk of secondary caries formation. In addition, in patients with high risk of caries, PDT can be a novel approach as a preventive protocol to control caries, although the high cost of PDT must be considered.

In addition to what is stated above, selection of an appropriate photosensitizer with related light source considering bacteria species should be taken into account in any photodynamic therapy and further studies on the effect of a-PDT, not only on single species of bacterial but on oral biofilms, are still required to obtain more definitive and certain results.

\section{CONCLUSION}

The results of the present study in its conditions demonstrated that $S$. mutans colonies were susceptible to either $62 \mathrm{~nm}$ laser or LED light in the presence of Radachlorin ${ }^{\circledR}$ and TBO respectively with no significant difference. Therefore, we can conclude that PDT with these photosensitizers may be helpful in caries preventive and treatment protocols.

\section{ACKNOWLEDGEMENT}

This work was supported (grant number: 89-0497-9916) by the Laser Research Center of Dentistry (LRCD), School of Dentistry, Tehran University of Medical Sciences, Tehran, Iran.

\section{REFERENCES}

1- Allaker RP, Douglas CW. Novel anti-microbial therapies for dental plaque-related diseases. Int J Antimicrob Agents. 2009;33(1):813.

2- Banfi S, Caruso E, Buccafurni L, Battini V, Zazzaron S, Barbieri P, et al. Antibacterial activity of tetraaryl-porphyrin photosensitizers: an in vitro study on Gram negative and Gram positive bacteria. J Photochem Photobiol B. 2006;85(1):28-38.

3- Baptista A, Kato IT, Prates RA, Suzuki LC, Raele MP, Freitas $A Z$, et al. Antimicrobial photodynamic therapy as a strategy to arrest enamel demineralization: a short-term study on incipient caries in a rat model. Photochem Photobiol. 2012;88(3):584-9.

4- Costa AC, Chibebe Junior J, Pereira CA, Machado AK, Beltrame Junior M, Junqueira JC, et al. Susceptibility of planktonic cultures of Streptococcus mutans to photodynamic therapy with a lightemitting diode. Braz Oral Res. 2010;24(4):413-8.

5- Douillard S, Lhommeau I, Olivier D, Patrice T. In vitro evaluation of Radachlorin sensitizer for photodynamic therapy. J Photochem Photobiol B. 2010;98(2):128-37.

6- Fekrazad R, Bargrizan M, Sajadi S, Sajadi S. Evaluation of the effect of photoactivated disinfection with Radachlorin $(\circledR)$ against Streptococcus mutans (an in vitro study). Photodiagnosis Photodyn Ther. $2011 ; 8(3): 249-53$.

7- George S Hamblin MR, Kishen A. Uptake pathways of anionic and cationic photosensitizers into bacteria. Photochem Photobiol Sci. 2009;8(6):788-95.

8- Giusti JS, Santos-Pinto L, Pizzolito AC, Helmerson K, CarvalhoFilho $E$, Kurachi $C$, et al. Antimicrobial photodynamic action on dentin using a light-emitting diode light source. Photomed Laser Surg. 2008;26(4):281-7.

9- Gursoy H, Ozcakir-Tomruk C, Tanalp J, Yilmaz S. Photodynamic therapy in dentistry: a literature review. Clin Oral Investig. 2013;17(4):1113-25.

10- Juzeniene A. Chlorin e6-based photosensitizers for photodynamic therapy and photodiagnosis. Photodiagnosis Photodyn Ther. 2009;6(2):94-6.

11-Kömerik N, Nakanishi H, MacRobert AJ, Henderson B, Speight $\mathrm{P}$, Wilson M. In vivo killing of Porphyromonas gingivalis by toluidine blue-mediated photosensitization in an animal model. Antimicrob Agents Chemother. 2003;47(3):932-40.

12- Kömerik N, Wilson M. Factors influencing the susceptibility of Gram-negative bacteria to toluidine blue O-mediated lethal photosensitization. J Appl Microbiol. 2002;92(4):618-23.

13- Lima JP, Sampaio de Melo MA, Borges FM, Teixeira AH, Steiner-Oliveira C, Nobre dos Santos M, et al. Evaluation of the antimicrobial effect of photodynamic antimicrobial therapy in an in situ model of dentine caries. Eur J Oral Sci. 2009;117(5):568-74. 14- Longo JP, Leal SC, Simioni AR, Fátima Menezes Almeida-Santos M, Tedesco AC, Azevedo RB. Photodynamic therapy disinfection of carious tissue mediated by aluminum-chloride-phthalocyanine entrapped in cationic liposomes: an in vitro and clinical study. Lasers Med Sci. 2012;27(3):575-84.

15- Mang TS, Tayal DP, Baier R. Photodynamic therapy as an alternative treatment for disinfection of bacteria in oral biofilms. Lasers Surg Med. 2012;44(7):588-96. 
16- Nagata JY, Hioka N, Kimura E, Batistela VR, Terada RS, Graciano AX, et al. Antibacterial photodynamic therapy for dental caries: evaluation of the photosensitizers used and light source properties. Photodiagnosis Photodyn Ther. 2012;9(2):122-31.

17- O'Neill JF, Hope CK, Wilson M. Oral bacteria in multi-species biofilms can be killed by red light in the presence of toluidine blue. Laser Surg Med. 2002;31(2):86-90.

18- Pereira CA, Romeiro RL, Costa AC, Machado AK, Junqueira JC, Jorge AO. Susceptibility of Candida albicans, Staphylococcus aureus, and Streptococcus mutans biofilms to photodynamic inactivation: an in vitro study. Laser Med Sci. 2011;26(3):341-8. 19- Rajesh S, Koshi E, Philip K, Mohan A. Antimicrobial photodynamic therapy: an overview. J Indian Soc Periodontol. $2011 ; 15(4): 323-7$.

20- Reshetnickov AV, Zalevsky ID, Kemov YV, Abakumova OY, Neugodova NP, Laptev VP, et al., inventors; RADA-PHARMA Co. Ltd., assignee. Photosensitizer, and process therefore. RF patent, 2183956. Oct. 10, 2002.

21- Rolim JP, de-Melo MA, Guedes SF, Albuquerque-Filho FB, Souza JR, Nogueira NA, et al. The antimicrobial activity of photodynamic therapy against Streptococcus mutans using different photosensitizers. J Photochem Photobiol B. 2012;106:406.

22- Suci P, Kang S, Gmür R, Douglas T, Young M. Targeted delivery of a photosensitizer to Aggregatibacter actinomycetemcomitans biofilm. Antimicrob Agents Chemother. 2010;54(6):2489-96.
23- Sullivan R, Santarpia P, Lavender S, Gittins E, Liu Z, Anderson $\mathrm{MH}$, et al. Clinical efficacy of a specifically targeted antimicrobial peptide mouth rinse: targeted elimination of Streptococcus mutans and prevention of demineralization. Caries Res. 2011;45(5):41528.

24- Usacheva MN, Teichert MC, Biel MA. Comparison of the methylene blue and toluidine blue photobactericidal efficacy against gram-positive and gram-negative microorganisms. Lasers Surg Med. 2001;29(2):165-73.

25- Vahabi S, Fekrazad R, Ayremlou S, Taheri S, Lizarelli RF, Kalhori KA. Antimicrobial photodynamic therapy with two photosensitizers on two oral streptococci: an in vitro study. Laser Phys. 2011;21(12):2132-7.

26- Vahabi S, Fekrazad R, Ayremlou S, Taheri S, Zangeneh N. The effect of antimicrobial photodynamic therapy with radachlorin and toluidine blue on streptococcus mutans: an in vitro study. J Dent (Tehran). 2011;8(2):48-54.

27- Wood S, Metcalf D, Devine D, Robinson C. Erythrosine is a potential photosensitizer for the photodynamic therapy of oral plaque biofilms. J Antimicrob Chemother. 2006;57(4):680-4.

28- Zanin IC, Gonçalves RB, Junior AB, Hope CK, Pratten J. Susceptibility of Streptococcus mutans biofilms to photodynamic therapy: an in vitro study. J Antimicrob Chemother. 2005;56(2):32430.

29- Zanin IC, Lobo MM, Rodrigues LK, Pimenta LA, Höfling JF, Gonçalves RB. Photosensitization of in vitro biofilms by toluidine blue $\mathrm{O}$ combined with a light-emitting diode. Eur J Oral Sci. 2006;114(1):64-9. 